\title{
On optimum temperature conditions for operation of portable aliminum-air batteries
}

\author{
Maxim Vlasenko ${ }^{1, *}$, Aleksey Bobylev ${ }^{1}$, Petr Galkin ${ }^{2}$, Sergey Kharlamov ${ }^{1}$, and Dmitry \\ Markovich $^{1}$ \\ ${ }^{1}$ Kutateladze Institute of Thermophysics, 630090 Novosibirsk, Russia \\ ${ }^{2}$ Nikolaev Institute of Inorganic Chemistry, 630090 Novosibirsk, Russia
}

\begin{abstract}
For construction of portable aluminium-air batteries (AABs) for field applications the data on performance of such batteries at low temperatures are necessary. Such experimental data are presented in this article. Lower temperature limit for effective operation of portable AABs is estimated. Possibility of AABs self-heating to the desired temperature is also considered.
\end{abstract}

\section{Introduction}

Aluminum-air battery ( $\mathrm{AAB})$ is an electrochemical power source in which aluminum is used as fuel and air oxygen is used as oxidant. Interest in the development of AABs is connected substantially with the fact that such batteries potentially have one of the highest specific energies in comparison with other types of batteries. At present, the main investigations concerning $\mathrm{AABs}$ are aimed at developing electrochemical generators with power sufficient for automotive applications $[1,2]$. An alkaline electrolyte is used in such generators and they are obligatory equipped with a loop of forced electrolyte circulation and regeneration to stabilize the electrolyte composition and temperature.

The effect of alkaline electrolyte composition and temperature on aluminum anode polarization and performance of aluminum-air cell with forced electrolyte circulation at heightened temperatures was investigated in detail in $[2,3]$. When concerning design of portable AABs, the results obtained in $[4,5]$ are useful. In these articles it is shown that main limitation of specific capacity at heightened temperatures for aluminum-air cells without any loop of electrolyte circulation is connected with anode passivation that occurs at the initial stage of aluminum hydroxide precipitation from electrolyte. At the same time for construction of portable AABs intended for field applications the data on performance of such cells at low temperatures are necessary. Such experimental data are presented in this article.

\section{Experimental technique}

${ }^{*}$ Corresponding author: vlasenko.maksim.g@gmail.com 
The experiments were carried out with prismatic cells, two sides of which were airbreathing gas diffusion cathodes (Fig. 1). The total area of the cathodes was $8 \mathrm{~cm} 2$. The electrolyte fill volume was $15 \mathrm{ml}$. The aluminum anodes in the form of plates $2 \mathrm{~cm}$ wide and $3 \mathrm{~mm}$ thick were placed between the cathodes through the center of the cells. The initial thickness of the gap between the anode and cathode was $4 \mathrm{~mm}$. Water solutions of $\mathrm{NaOH}$ with the initial concentration from 3 to $8 \mathrm{M}$ were used as electrolyte. Since aluminum anodes are prone to strong corrosion in the alkaline electrolytes, in our experiments we dope the electrolyte with $0.02 \mathrm{M}$ sodium stannate as corrosion inhibitor which allowed reducing the rate of aluminum corrosion by more than one order of magnitude in a wide temperature range.

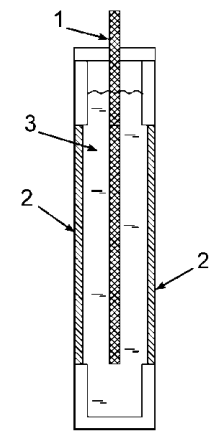

Fig. 1. Layout of the experimental cell. 1 - aluminum anode, 2 - air cathode, 3 - electrolyte.

The cells were discharged through resistive load of $2 \mathrm{Ohm}$, which provided discharge current densities at a level of $60-90 \mathrm{~mA} / \mathrm{cm}^{2}$ at operating voltages of 1.0-1.4 V. Simultaneously with the operating voltage of the cells, we measured the running temperature of the electrolyte in the cells. Since the discharge of the cells is accompanied by release of a great amount of heat, the electrolyte temperature in the cells with natural cooling can be several tens degrees higher than ambient temperature and can significantly vary during discharging. To stabilize the temperature of electrolyte, the cells were placed into the climate chamber with forced convection of air whose humidity was maintained at a level of $50 \%$. Under such conditions, the electrolyte temperature in the working cells exceeded the ambient temperature by not more than $2-3{ }^{\circ} \mathrm{C}$. The capacity of the cells was determined as time integral of discharge current until the point when voltage across the resistive load began to decrease rapidly. An example of discharge characteristics of the cells with different concentration of electrolyte are shown in Fig. 2.

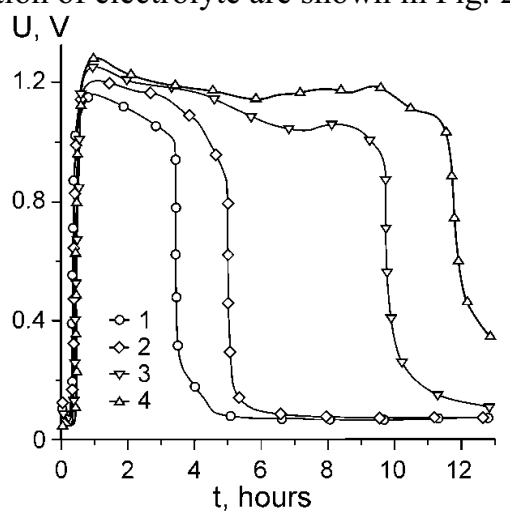

Fig. 2. Discharge characteristics of the cells with analytical grade aluminum anode at $\mathrm{T}=32{ }^{\circ} \mathrm{C}$. NaOH concentration: $1-3 \mathrm{M}, 2-4 \mathrm{M}, 3-6 \mathrm{M}, 4-8 \mathrm{M}$. 
The working material of anodes was analytical grade aluminum (with aluminum content not less than $99.82 \%$ ) and anode alloys of composition $\mathrm{Al}-0.4 \% \mathrm{Mg}-0.2 \% \mathrm{In}-0.02 \%$ Ga (AMIG system). According to the data of [5], in contrast to pure aluminum the latter alloy is not passivated and continues to work at high working current densities after the beginning of aluminum hydroxide precipitation which results in sufficient increase of aluminum-air cells capacity.

\section{Experimental results}

The effect of electrolyte operating temperature on the cell specific capacity is shown in Fig.3. As can be seen, at electrolyte temperature lower than $+30{ }^{\circ} \mathrm{C}$ the cell specific capacity diminishes with decrease of the temperature so rapidly that at $+15^{\circ} \mathrm{C}$ it is not more than $20-25 \%$ of the specific capacity at $+40{ }^{\circ} \mathrm{C}$ independently of the anode alloy composition. In the range of operating temperatures between $+30^{\circ}$ and $+50^{\circ}$ the cell specific capacity has a weak temperature dependence and is equal to about $400 \mathrm{Ah}$ per litre of electrolyte when anode is made of pure aluminum and about $500 \mathrm{Ah} / \mathrm{L}$ for AMIG alloy anodes.

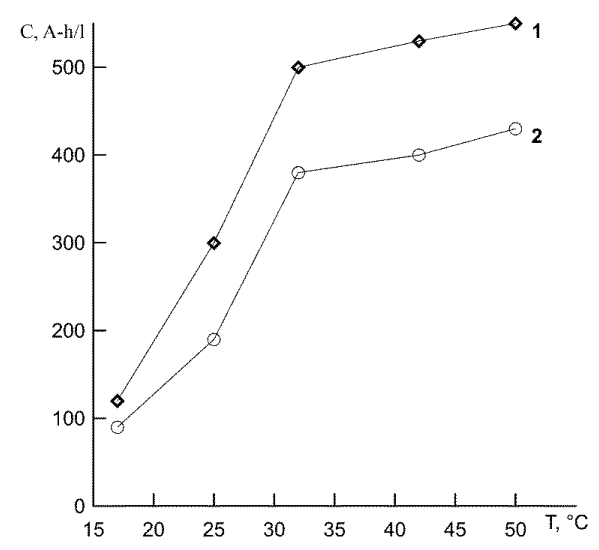

Fig. 3. Dependence of specific cell capacity on electrolyte temperature. 1 - AMIG alloy anode, 2 analytical grade aluminum anode.

Thus, to ensure high specific capacity of AABs the electrolyte temperature in operating battery should be maintained at the level higher than $+30{ }^{\circ} \mathrm{C}$ at any ambient temperature. In working $\mathrm{AAB}$ such temperature of electrolyte can be maintained due to the heat released during its operation [3]. However when AAB remains for a long time in standby mode at low ambient temperatures the problem of its quick self-heating to operating temperatures, for instance, by operating in short circuit mode, is arising. Our studies of dependence of short-circuit current density on the cell operating temperature showed that this dependence is exponential and for different anode alloys short-circuit current grows 2.2-2.5 times per temperature increase of $10^{\circ}$ (Figure 4). Therefore, when electrolyte temperature falls below $+20{ }^{\circ} \mathrm{C}$ quick self-heating of AABs to the operating temperatures appears impossible, and this means that at low ambient temperatures an $\mathrm{AAB}$ in standby mode has to use a part of its energy to maintain inner temperature at a sufficiently high level. 


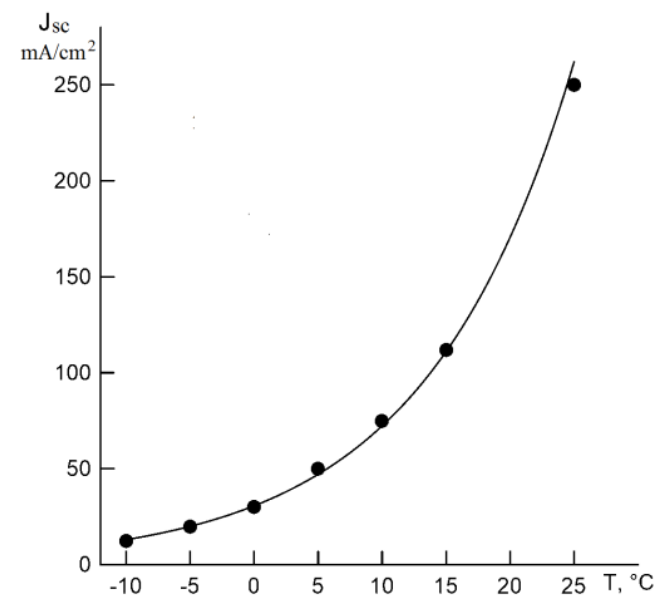

Fig. 4. Dependence of short-circuit current density on the cell operating temperature. Analytical grade aluminum anode.

In conclusion, our results show that when designing portable aluminum-air batteries for field applications it is important to consider that electrolyte temperature in $\mathrm{AAB}$ has to be maintained at the level higher than $+30^{\circ} \mathrm{C}$. Non-fulfillment of this requirement may result in sharp deterioration of $\mathrm{AAB}$ performance.

This work is supported by program of RAS (project "Development of the fundamentals of aluminum-air batteries for the Arctic" (0322-2015-0001)).

\section{References}

1. S. Yang, H. Knickle, J. Power Sour. 112, 162 (2002)

2. A. Zhuk, A. Ilyukhina, A. Ilyukhin, B. Kleimenov, M. Nagayama, Elektrokhim. Energet. 13, 83 (2013)

3. A. Ilyukhina, A. Zhuk, B. Kleymenov, A. Ilyukhin, M. Nagayama, Fuel Cells, 16, 384 (2016)

4. S. Alekseenko, A. Bobylev, P. Galkin, D. Markovich, S. Kharlamov, J. Eng. Thermophys. 23, 280 ( 2014)

5. S. Kharlamov, A. Bobylev, P. Galkin, K. Dobroselsky, M. Vlasenko, D. Markovich, J. Eng. Thermophys. 24, 313 (2015) 